\title{
Structure and Chromosomal Localization of the Mammalian Agrin Gene
}

\author{
Fabio Rupp, ${ }^{1}$ Tayfun Ǒzçelik, Michal Linial, ${ }^{1}$ Karen Peterson, ${ }^{1}$ Uta Francke, ${ }^{2}$ and Richard Scheller ${ }^{1}$ \\ Howard Hughes Medical Institute, 'Department of Molecular and Cellular Physiology, and 'Departments of Genetics and \\ Pediatrics, Stanford University School of Medicine, Stanford, California 94305
}

\begin{abstract}
Agrin, a component of the synaptic basal lamina, has been shown to induce clustering of ACh receptors on the surface of muscle fibers. Analysis of cDNAs isolated from a rat embryonic spinal cord library demonstrated that agrin contains domains similar to regions of protease inhibitors, laminin and epidermal growth factor. The domain structure of agrin is further revealed here in an analysis of the agrin gene. Two additional internal repeated sequences are defined: one rich in cysteine residues with no homology to other proteins, and another similar to the laminin G domain, which is involved in heparin binding. Alternative RNA splicing at two positions in the gene predicts up to eight possible forms of the agrin protein. The gene (symbol AGRN/Agrn) has been assigned to chromosome 1 region pter-p32 in human and to mouse chromosome 4.
\end{abstract}

Interactions between cells and components of the extracellular matrix mediate aspects of growth, migration, and differentiation. In the nervous system, the extracellular matrix of the neuromuscular junction is enriched in molecules that may have important roles in synaptic function and development (Hall, 1973; Bayne et al., 1984; Hunter et al., 1989). Onc of thesc synaptic matrix proteins, agrin, was recognized for its ability to induce clusters of ACh receptors (AChRs) when applied to muscle fibers in culture (Godfrey et al., 1984; Fallon et al., 1985; Nitkin et al., 1987). Early in development, AChRs are randomly distributed along muscle fibers. However, as nerve-muscle contacts are made, receptors redistribute beneath the presynaptic terminal in a position appropriate for neurotransmitter response (Fertuck and Salpeter, 1974, 1976; Anderson et al., 1977; Bevan and Steinbach, 1977; Weinberg et al., 1981; Schuetze and Role, 1987). The results obtained with agrin from marine ray electric organ and recombinant sources suggest that it may mediate this nerve-induced receptor clustering on developing muscle fibers.

Agrin is synthesized in the nerve cell body (Magill-Solc and McMahan, 1988; Rupp et al., 1991), is transported down the axon via anterograde transport (Magill-Solc and McMahan, 1990), and is specifically localized to the synaptic basal lamina. Agrin-induced clusters of AChR also contain high concentrations of AChE, heparan sulfate proteoglycan, and a $43 \mathrm{kDa}$

\footnotetext{
Received Feb. 18, 1992; accepted April 3, 1992.

Correspondence should be addressed to Richard H. Scheller, Howard Hughes Medical Institute, Department of Molecular and Cellular Physiology, Stanford University, Stanford, CA 94305 . This work was supported in part by Binational Science Foundation Grant 89-00209 to R.H.S. and M.L. and Grant H600298 to U.F.

Copyright (c) 1992 Society for Neuroscience $0270-6474 / 92 / 123535-10 \$ 05.00 / 0$
}

protein, suggesting that agrin may regulate the organization of multiple synaptic components (Wallace, 1986, 1989; McMahan and Wallace, 1989; Nitkin and Rothschild, 1990). The presence of agrin immunoreactivity in the basal lamina of damaged synapses suggests that agrin may also play a role in the regeneration of the neuromuscular junction (Reist et al., 1987).

The mechanism of agrin action is unknown. However, recent studies suggest that (1) in chick, phosphorylation of tyrosine residues in the $\beta$-subunit of the $\mathrm{ACh}$ receptor precedes aggregation (Peng et al., 1991; Qu et al., 1991; Wallace et al., 1991), and (2) a $43 \mathrm{kDa}$ protein associated with the intracellular aspect of the AChR promotes clustering (Froehner et al., 1990; Froehner, 1991; Phillips et al., 1991). Thus, agrin may act through tyrosine kinase(s) and the $43 \mathrm{kDa}$ protein to localize $\mathrm{AChR}$ at synaptic sites.

One approach to understand further the function of agrin during synapse formation and regeneration is analysis of the amino acid sequence. To this end, Rupp et al. (1991) characterized a set of clones isolated from an embryonic spinal cord cDNA library. The protein predicted from analysis of these clones contains an N-terminal hydrophobic sequence that may act as a signal peptide. The agrin protein is composed of several domains, including nine regions homologous to Kazal-type protease inhibitors, a region showing significant amino acid identity with the extracellular matrix protein laminin, two serine/threonine-rich domains that may be sites of O-linked glycosylation, and four regions similar to repeats found in epidermal growth factor (EGF). A 9 amino acid sequence was found to be present in one set of clones and absent from another, suggesting alternative RNA splicing may generate multiple agrin proteins. Northern blotting and in situ hybridization demonstrated that the transcript is most abundant in the embryonic nervous system, including motor neurons. Lower transcript levels are also found in embryonic muscle. Agrin immunoreactivity was shown to be localized to the synaptic cleft of the rat neuromuscular junction, where the protein appears as an approximately 210 kDa species in Western blotting experiments (Rupp et al., 1991).

The full-length rat agrin protein has been expressed in $\mathrm{CHO}$ and COS cells. In these transfected cells, immunoreactivity is detected in the endoplasmic reticulum and Golgi region, as well as the extracellular surface where the protein is associated with extracellular matrix. When the agrin-transfected cells are cocultured with rat muscle fibers, AChRs are localized at high density to transfected cell-muscle cell contact sites (Campanelli et al., 1991). Together, these data suggest that agrin mediates the neuron-induced clustering of $\mathrm{AChR}$ at synaptic sites during development (McMahan and Wallace, 1989; Campanelli et al., 1991; Rupp et al., 1991). 
In the present study, we further define the domain structure of alternatively spliced agrin proteins. The genomic organization underlying the alternative splicing is presented along with the chromosomal location of the gene in mouse and human.

\section{Materials and Methods}

$P C R$ reactions and alternative splicing. The numbering of bases and amino acids is as described in Rupp et al. (1991). Single-stranded cDNA (ss cDNA, $0.1 \mu \mathrm{g}$ ) was synthesized from rat embryonic day 17 spinal cord polyA ${ }^{+}$RNA using Moloney murine leukemia virus reverse transcriptase, as recommended by the manufacturcr (Bethesda Rescarch Labs). PCR reactions were performed in $1 \times$ PCR buffer (Perkin Elmer Cetus), $10 \mathrm{U}$ of Taq polymerase (Perkin Elmer Cetus), and $0.2 \mu \mathrm{M}$ concentrations of each primer using $0.5 \mathrm{ng}$ of ss cDNA preheated $5 \mathrm{~min}$ at $97^{\circ} \mathrm{C}$. The primers correspond to rat agrin nucleotides $5184-5204$ and to the reverse complement of rat agrin nucleotides 6016-6034 with an added $\mathrm{Xbal}$ restriction site at the $3^{\prime}$ end. The amplification protocol was 60 cycles of $1.15 \mathrm{~min}$ denaturing steps at $94^{\circ} \mathrm{C}$, followed by extension steps of $2.3 \mathrm{~min}$ at $72^{\circ} \mathrm{C}$. The PCR products were separated on a $2 \%$ agarose gel and purified following the Geneclean protocol (Bio 101). Aliquots of the purified PCR products were subcloned into Bluescript KS-(Stratagene). Combinations of internal primers were used to amplify aliquots of purified PCR products further. The primers were from rat agrin nucleotides 5392-5411, and reverse complement nucleotides 57925811 . The amplification conditions were the same as decribed above, except the extension was done in two steps of $1.15 \mathrm{~min}$ each at $60^{\circ} \mathrm{C}$ and $72{ }^{\circ} \mathrm{C}$. The reamplified PCR products were separated on a $2.2 \%$ agarose gel, purified, subcloned into Bluescript KS-, and sequenced using the Sequenase 2 kit (U.S. Biochemicals).

Oligonucleotides specific for the 8 and the 11 amino acid differentially spliced exons were used to screen the original PCR product subclones. Hybridizations were performed at $57^{\circ} \mathrm{C}$ in $5 \times$ saline-sodium citrate (SSC), $5 \times$ Denhardt's solution, $0.5 \%$ SDS, $150 \mu \mathrm{g} / \mathrm{ml}$ Escherichia coli tRNA (Sigma), and $10^{6} \mathrm{cpm} / \mathrm{ml}$ of a $4 \times 10^{6} \mathrm{cpm} / \mathrm{pmol}$ labeled oligonucleotide. About $2.5 \%$ of the total colonies were positive for either probe.

Genomic library screening and sequencing. Plaques $(500,000)$ of a lambda FixII genomic library constructed with DNA isolated from a mouse PCC4 cell line (Stratagene) were screened using a rat agrin cDNA probe (nucleotides 3414-4069). Hybridization was carried out overnight at $55^{\circ} \mathrm{C}$ in $5 \times \mathrm{SSC}, 5 \times$ Denhardt's solution, $0.5 \% \mathrm{SDS}$, and $150 \mu \mathrm{g} / \mathrm{ml}$ tRNA. The filters were washed once for $10 \mathrm{~min}$ at room temperature in $1 \times \mathrm{SSC}, 0.1 \% \mathrm{SDS}$ and twice for $20 \mathrm{~min}$ at $55^{\circ} \mathrm{C}$ with $0.1 \times \mathrm{SSC}$, $0.1 \%$ SDS. Digestion of the positive clone with NotI revealed a 16 kilobase $(\mathrm{kb})$ insert. After further digestion with HindIII and BamHI restriction enzymes, five fragments were obtained. In the $5^{\prime}$ to $3^{\prime} \mathrm{di}$ rection, the fragments were N/B $(1.5 \mathrm{~kb}), \mathrm{B} / \mathrm{B}(2.5 \mathrm{~kb}), \mathrm{B} / \mathrm{H}(5.4 \mathrm{~kb})$, $\mathrm{H} / \mathrm{H}(4.8 \mathrm{~kb})$, and $\mathrm{H} / \mathrm{N}(1.8 \mathrm{~kb})$, respectively (see Fig. 3). These fragments were individually subcloned into the Bluescript $\mathrm{KS}+$ vector from Stratagene. $\mathrm{CsCl}$-prepared DNA from the recombinant plasmid was sequenced using the dideoxy chain termination method with the Sequenase kit. Both oligonucleotides specific for the rat agrin cDNA clone and for the mouse genomic clone were used as primers in the sequencing reactions.

cDNA library screening and sequencing. A human agrin cDNA clone was obtained by screening 500,000 plaques of a lambda ZapII cDNA library constructed from human fetal brain cDNA (Stratagene). A rat agrin CDNA, as above, was used as a probe. Hybridization was carried out overnight at $60^{\circ} \mathrm{C}$ in the same hybridization buffer as described above. The filters were washed once for $20 \mathrm{~min}$ at $60^{\circ} \mathrm{C}$ in $1 \times \mathrm{SSC}$, $0.1 \%$ SDS and once for $20 \mathrm{~min}$ at $60^{\circ} \mathrm{C}$ in $0.1 \times$ SSC, $0.1 \%$ SDS. An insert from a positive agrin clone was isolated by in vivo excision of the Bluescript plasmid from the lambda ZapII vector and shown to contain a $5.2 \mathrm{~kb}$ insert. The insert was partially sequenced by the dideoxy chain termination method revealing strong identity with the nucleotide and predicted amino acid sequence of rat agrin.

Hybrid cell lines. The chromosomal location of the human agrin gene has been determined by Southern blot analysis using a $2.1 \mathrm{~kb}$ Notl subclone of the human agrin cDNA clone. The probe was hybridized to a human mapping panel of 14 Chinese hamster $\times$ human somatic cell hybrids from series XII, XV, XVII, XVIII, XXI, and 31. The mouse gene was assigned with a mouse mapping panel of 12 Chinese hamster $x$ mouse hybrids from fusions I, EAS, and EBS. The hybrid that was used for the regional assignment in human was from fusion of human cells with a balanced reciprocal translocation $\mathrm{t}(1 ; 6)(\mathrm{p} 32 ; \mathrm{p} 21)$ (hybrid series XV). The derivation of hybrid cell lines has been summarized elsewhere (Francke et al., 1986). Five different inbred mouse strains, $\mathrm{AKR} / \mathrm{J}, \mathrm{C} 3 \mathrm{H} / \mathrm{HeJ}, \mathrm{C} 57 \mathrm{BL} / 6 \mathrm{~J}, \mathrm{C} 57 \mathrm{~L} / \mathrm{J}$, and DBA $2 \mathrm{~J}$ from The Jackson Laboratory, Bar Harbor, ME, were used for polymorphism search with the agrin probe.

Southern blot hybridization. Genomic DNA was extracted from hybrids and parental control cell lines by standard methods. DNA samples were digested with restriction endonucleases, separated by agarose gel electrophoresis, transferred to Hybond nylon filters (Amersham), and hybridized to ${ }^{32} \mathrm{P}-$ labeled probes according to methods described elsewhere (Barton et al., 1986).

\section{Results}

Multiple forms of agrin are expressed in embryonic spinal cord. Analysis of agrin cDNA clones isolated from an embryonic spinal cord library revealed two forms differing by 9 amino acids (Fig. 1A) (Rupp et al., 1991). Since the remainder of overlapping sequence from these clones is identical, the difference is most likely the result of alternative RNA splicing. In addition, a variety of cDNA clones encoding multiple agrin-related proteins have been isolated from chicken cDNA libraries (McMahan, 1990). To characterize forms of mammalian agrin further, PCR was used to amplify cDNA synthesized from rat embryonic day 17 spinal cord RNA. Sequence analysis of a set of the cloned PCR products predicts four forms of agrin (Fig. $1 B$ ). The forms differ at amino acid 1779 , where four variations in sequence are identified: (1) no insert sequences, (2) an 8 amino acid insert, (3) an 11 amino acid insert, or (4) a 19 amino acid insert consisting of both the 8 and the 11 amino acid sequences. Each of these variants has been observed in multiple independent clones.

At this stage of rat development, about $90 \%$ of all agrin transcripts in spinal cord encode the variant lacking additional sequences at amino acid position 1779 . The other three variants represent about $10 \%$ of the agrin cDNA in embryonic spinal cord (data not shown). The sequences inserted at position 1779 contain charged amino acids, as well as several proline residues. The polar character of the inserts suggests that they lie on the surface of the molecule. The prolines do not favor helical structures. Since the identification of these sequence variants comes from partial cDNA clones or PCR products, we have not yet determined whether all of the eight possible combinations of sequences occur in vivo.

Organization of the agrin gene. To understand better the domain structure and the mechanism underlying the synthesis of alternative forms of agrin, we isolated and characterized most of the coding region of the mouse agrin gene. The mouse genomic clone we have characterized is a $16 \mathrm{~kb}$ NotI restriction enzyme fragment and was shown by Southern blotting experiments to contain sequences homologous to most of the rat cDNA. Five subfragments of the NotI fragment were subcloned and the nucleotide sequence of each determined, as described in Materials and Methods. The genomic fragment contains 36 exons beginning at the first protease inhibitor domain and extending through the 3' untranslated region. We have not found the exon sequences predicted to encode the initiator methionine and the signal sequence. This suggests an intron greater than $1.35 \mathrm{~kb}$ separates this region of the gene from the main body of coding sequences. With the exception of the $3^{\prime}$ untranslated region, the exons are quite small; the largest is 333 base pairs while the smallest is 12 base pairs. Similarly, the introns are also generally small; the largest intron is only 712 base pairs, while the smallest is 65 base pairs.

The intron/exon pattern of the agrin gene displays a remark- 

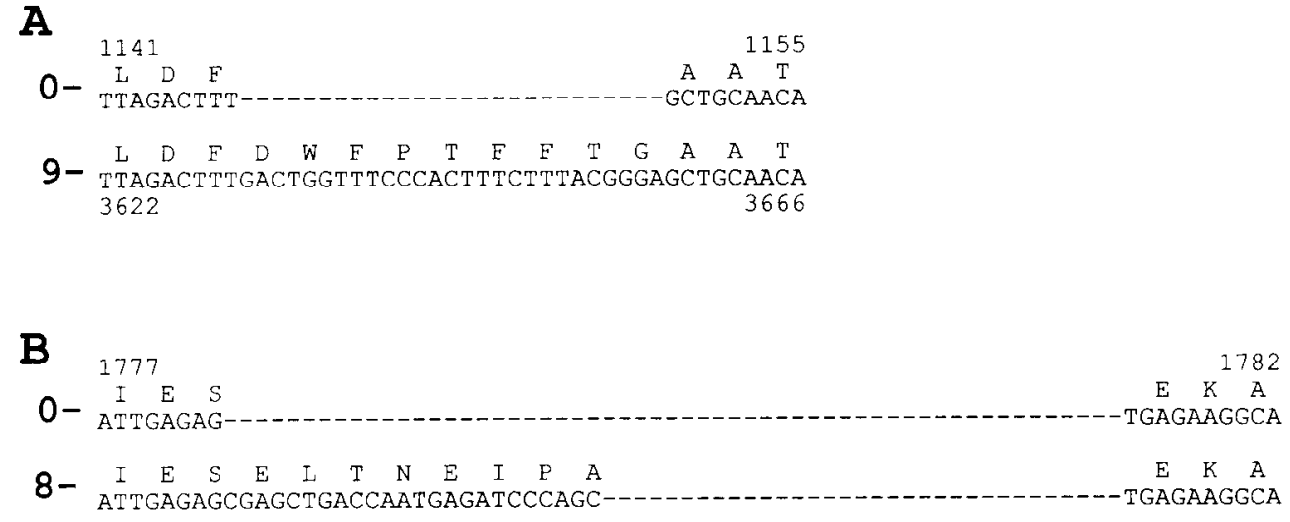

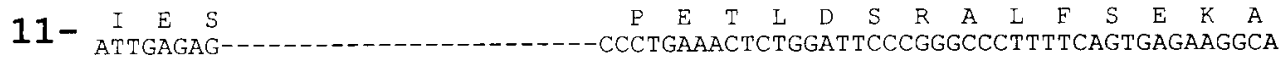

19- $\begin{aligned} & 1 \\ & \text { ATTGAGAGCGAGCTGACCAATGAGATCCCAGCCCCTGAAACTCTGGATTCCCGGGCCCTTTTCAGTGAGAAGGCA }\end{aligned}$ 5530
Figure 1. Multiple agrin isoforms. The nucleotide and amino acid sequences of multiple agrin isoforms are presented. The amino acid number is written above the sequence and the nucleotide sequence is written below according to Rupp et al. (1991). A, Two variants differing by 9 amino acids are found at amino acid position 1143. $B$, Four alternative sequences are observed at position 1779. One variant contains an insert of 8 amino acids, a second variant has an insert of 11 amino acids. while a third variant contains a 19 amino acid insert that comprises the 8 and the 11 amino acid sequences. able correspondence to the previously suggested domain structure of the protein (Figs. 2, 3) (Rupp et al., 1991). The first seven protease inhibitor domains are each encoded on separate exons. Protease inhibitor domains 8 and 9 are also flanked by introns, but also contains an intron within the domain. The relative position of this "internal" intron is identical, even though the degree of amino acid identity between these exons is no greater than that between protease inhibitor domains $1-7$, which do not contain an internal intron.

Exon number 10 (39 amino acids) displays $22 \%$ amino acid sequence identity to exon number 16 (46 amino acids). Alignment of the carboxy terminal amino acids of these two exons demonstrates that 10 amino acids occur in identical positions (Fig. $4 A$ ). Of these 10 identical positions, four are cysteine resjdues and three are proline residues. These domains do not show any significant homology to other proteins in the data base. However, the identical locations of the cysteine and proline residues suggest that they may participate in creating a repetitive tertiary structure.

The carboxy terminal 800 amino acids contain three additional repeated sequences. These 110 amino acid sequences share extensive amino acid identity and similarity (Fig. 4B), clearly demonstrating that internal duplications have contributed to the evolution of this portion of the agrin protein. The first and third repeats are each encoded on two exons; 21-22 and 35-36, respectively. The second repeat contains 4 amino acids that are not found in repeats 1 and 3 . These amino acids are encoded on a distinct exon (exon 28), and thus repeat 2 is encoded on a total of 4 exons (exons 26-29) (Fig. 4B). The 4 amino acid exon is the smallest in the gene and encodes the sequence KSRK. Surprisingly, these repeated regions share significant sequence homology with the $\mathrm{G}$ domain of the laminin A chain (Sasaki et al., 1988) and with merosin (Ehrig et al., 1990). Both merosin and laminin $A$ contain five internal repeated regions denoted Gl-G5. The three agrin repeated regions share highest homology to laminin $A G 1$ and $G 2$, and to merosin $G 1, G 2$, and $G 4$ domains.

Exons 11 and 12 encode a cysteine-rich region of the agrin protein that is similar to type A repeats in laminin domain III. We proposed that this region evolved through an internal duplication, a hypothesis that is supported by the genomic organization (Rupp et al., 1991). The first of two serine- and thre- onine-rich regions is encoded by a distinct exon (exon 15), whereas the second is encoded by an exon that also contains the first EGF-repeat sequence (exon 20). The serine- and threonine-rich regions have been suggested to be O-linked glycosylation cassettes. While we do not have information regarding their specific function, the genomic organization supports a hypothesis that these regions of the molecule have distinct functions. The remaining three EGF-repeat sequences are not encoded on distinct exons; however, EGF repeats 3 and 4 contain intervening sequences at their carboxy terminal aspect. The carboxy terminal 52 amino acids are coded by a single exon that includes the 3 ' untranslated portion of the mRNA.

Alternative RNA splicing generates multiple forms of agrin. Many extracellular matrix protein isoforms are generated by alternative RNA splicing. Examples include elastin (Indik et al., 1987), fibronectin (Kornblihtt et al., 1985; Schwarzbauer et al., 1987), and collagen (Pihlajaniemi et al., 1987; Tikka et al., 1987; Svoboda et al., 1988; Ryan and Sandell, 1990). In addition, some of the splicing patterns display species and tissue specificity (see Andreadis et al., 1987, for a review). Indeed the differences in the predicted agrin protein sequences described above arise from two different modes of alternative RNA splicing. The donor site of exon 19 can be spliced to either of two receptor sites separated by nine amino acids on exon 20 (Figs. 2, 3). Four possibilities arise for the splicing of exons $31,32,33$, and 34 (Figs. 2, 3). Exon 31 can be directly joined to exon 34, skipping the sequences encoded by exons 32 and 33 . This splices out the longest intervening sequence of the coding region. Alternatively, exon 31 can be spliced to exon 32 and then to 34 , skipping exon 33 , or exon 31 can be spliced to exon 33 and then to 34 , skipping exon 32 . These patterns give rise to the 8 and the 11 amino acid inserts detected in the PCR amplification of embryonic spinal cord cDNA. The final pattern is generated by joining exons 31 , 32,33 , and 34 in sequence and accounts for the 19 amino acid sequence found in the spinal cord cDNA.

Isolation of a human agrin $c D N A$. Since the mouse genomic fragment used to probe the human chromosome mapping blots hybridized weakly, we isolated a human agrin cDNA clone from an embryonic brain cDNA library (see Materials and Methods). To confirm the identity of the human cDNA clone, the nucleotide sequence was determined using the $\mathrm{T} 7$ primer. The region sequenced was at the $5^{\prime}$ end of the cDNA and encodes 61 amino 


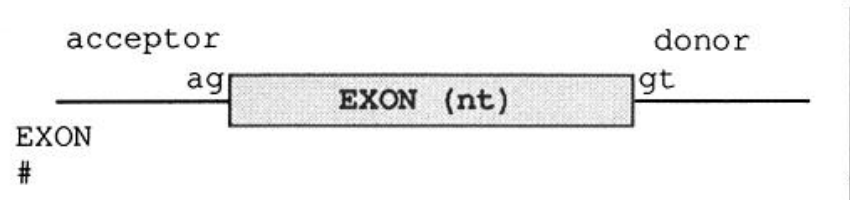

$66-\mathrm{V} \quad \mathrm{C}$

1 aaactcagtGTGC

138-G S

2 acccacagGGTCC

213-D P

3 gactctagACCCC

288-D Q

4 attcccagACCAG

357-D Q

5 tgctctagACCAG

430-D R

6 ttccccagACCGA

495-Q T

7 ctctgtagAGACC

562-A E

8 tcctqcagCTGAG

612-V C

9 ctcctcagGTGTGT

647-G P

10 ttcctcagGCCCT

$$
\text { 686-S T }
$$

11 cettgtagGCACC

$$
\text { 741-P C }
$$

12 ctccccagCCTGC

$$
\text { 789-D P }
$$

13 tatctcagATCCC

$$
\text { 831-V C }
$$

14 gcctccagGTCTGT

866-E S

15 ttttgcagAGAGT

977-G L

16 tccccaagGACTT

1023-A T

17 ccccacagCTACC

1066-L D

18 tagaacagCTGGAC
C-137

216 TGTGgtaagtaa

C-212

R-287

225 CGAGgttcggtg

C-356

207 TGTGgtgagcag

C- 429

219 TGTGgtcagtgg

C-494

195 TGCCgtgagtgg

P-561

201 CCGGgtaagctc

S P-611

149 AGCCCAgtgagtac

$R-646$

106 CGGGgtgagtgg

$\mathrm{P}-685$

117 CCCAgtgtgtat

$\mathrm{T}-740$

165 ACTCgtggtaat

A-788

144 GCAGgtgagggc

T $\mathrm{K}-830$

125 ACCAAGgtagagga

$R-865$

106 CGGGgtaaggac

G-976

333 GGGGgtgagcag

P-1022

138 CCAGgtgagtga

S T-1065

131 AGCACGgtatgagg

P-1103

115 CCCAgtaagccc
225 TGTGgtaagcga

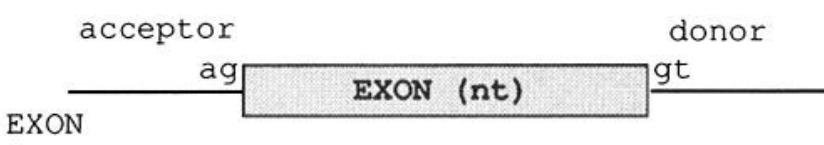

\#

F-1143

19 ctccccagCCACA

120

TTTGgtgagtac

1144-D W

20 a ccctgcagACTGG

348

K-1259

1153-A A

20b tacgggagCTGCA

1260-V Q

21 tcctgcagTGCAA

193

F R-1324

1325-F

22 gtgttagGTTC

216

1397-V

23 ggtatcagGGTG

230

1473-G P

24 cectcagGCCCA

1518-V L

25 ctccatagTCCTG

1551-E

26 gaccccagGGAG

1606-S

27 ttttgcagGAGC

1643-K S

28 gatgtcagAAATCC

1647-V P

29 tcctgtagGTCCCG

1686-V S

30 ttcttcagGTGTCT

1750-G

31 tctcccagGGGA

\section{7}

97

165

112

S P-1642

TCTCCGgtgagtat

R K-1646

12

CGCAAGgtaccgca

Q L-1685

117 CAGCTGgtacggag

E R-1749

191 GAGAGgtgagcat

E $\quad$ S-1779

90

GAGAGgtaacgtg

32 tttacaagCGAG

P A

24 CCAGCgtaagtag

$33 \stackrel{P}{\text { tctcaaagCCCC}}$

F S

33 TTCAGgtaagcac

H R-1854 n

225

CACAGgtcagtga

L-1888

1855-E

35 tctcctagGGAG

104

CTTGgttagtgt

1889-G G

36 gtctgtagGAGGC
T L $\quad$ *-1941

1411 ACTCTCTGA--A 

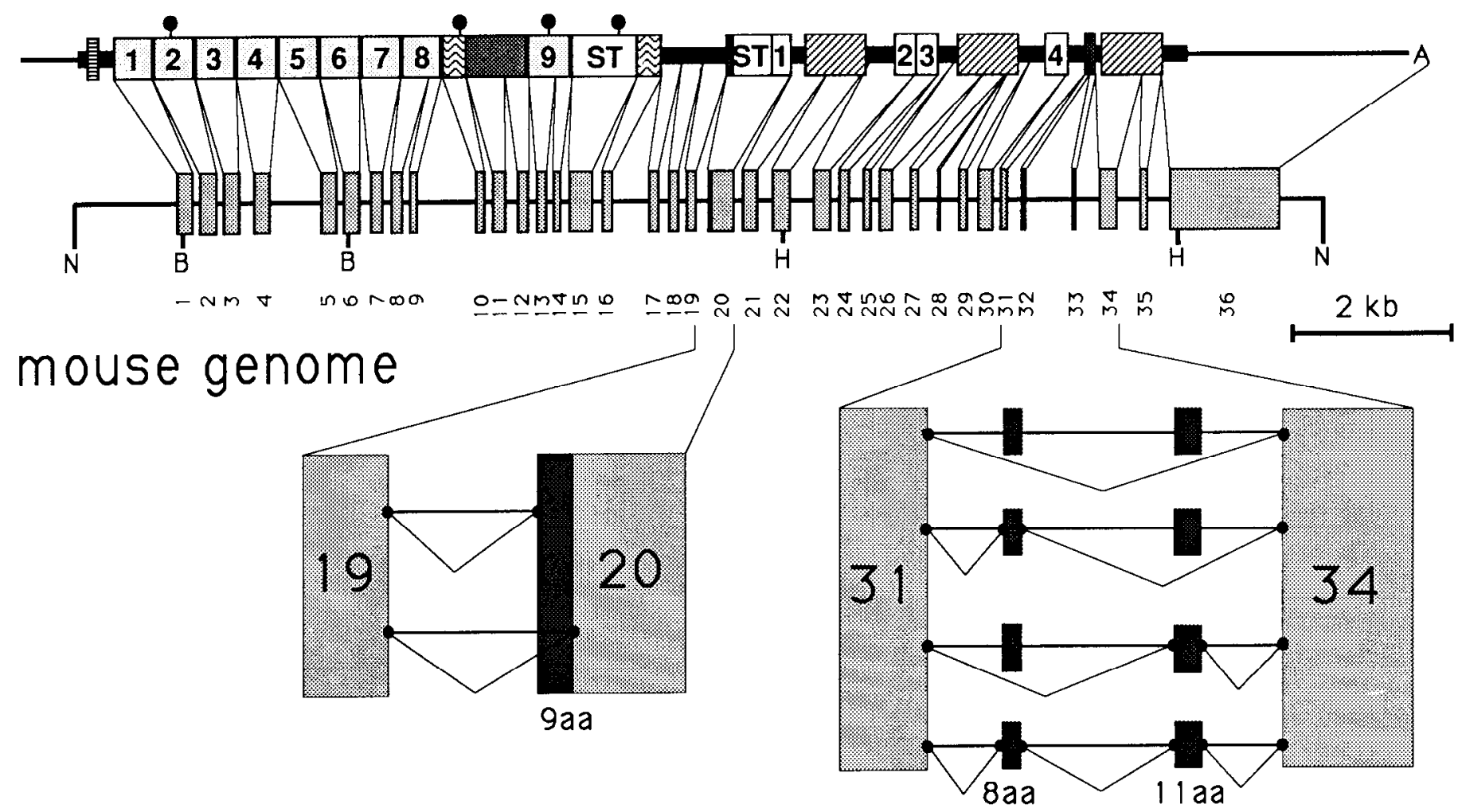

Figure 3. Alternative RNA splicing generates multiple agrin proteins. A schematic of the rat agrin cDNA is presented along with the domain structure of the protein. The initiator methionine is followed by a hydrophobic signal sequence (1). Nine domains are similar to Kazal-type protease inhibitors $(\square 1-9)$, and a single region is similar to domain III of laminin ( $\square$ ). Two cysteine-rich regions of the agrin protein display internal sequence homology (圆), and three domains in the carboxy terminal half of the molecule share significant sequence identity (圈). The agrin protein contains four EGF-repeats in the carboxy terminal half of the molecule $(\square \mathrm{l}-4)$. Two regions are rich in serine and threonine $(S T)$, and there are four potential $\mathrm{N}$-linked glycosylation sites ( $)$. Two portions of the protein are found in multiple configurations generated by alternative RNA splicing $(\mathbf{i})$. The untranslated region of the rat cDNAs end in a polyA tail $(A)$. A schematic of the mouse genomic region encoding agrin is depicted. The exons are indicated by boxes, numbered $1-36$, and connected to their respective regions on the cDNA. The restriction enzyme sites used to subclone genomic regions for sequencing are indicated; $N$, NotI; $B$, BamHI; $H$, HindIII. The patterns of alternative RNA splicing are depicted.

acids. In the 188 nucleotides of sequence obtained, there are 29 differences from the rat cDNA; 4 occur in the first codon position, 6 occur in the second codon position, and 19 occur in the third position (Fig. 5). These substitutions result in nine predicted amino acid replacements. Interestingly, four of the amino acid replacements have two or more nucleotide substitutions, while five are the result of only a single base change. The region sequenced corresponds to protease inhibitor domain 7, which may be particularly highly conserved when compared to other domains of the molecule. The data demonstrate that we have indeed isolated a human agrin homolog useful for chromosome mapping experiments.

Mapping of human agrin. The human agrin gene (gene symbol AGRN) was mapped with a BamHI-digested mapping panel of Chinese hamster $\times$ human somatic cell hybrids that carry reduced numbers of human chromosomes. The $2.1 \mathrm{~kb}$ human probe hybridizes to an $11 \mathrm{~kb}$ human and an $8 \mathrm{~kb}$ Chinese hamster fragment (Fig. 6, left, lanes 1 and 2, respectively). The 11 kb human fragment was concordant with human chromosome 1. All other chromosomes were excluded by at least two discordant hybrids (Table 1). One hybrid cell line from fusion series $\mathrm{XV}$ that carried human chromosome 1 region $\mathrm{p} 32$-qter, in the absence of an intact copy of this chromosome, was negative for the human signal. Therefore, we assign the AGRN locus to the distal short arm region 1 pter-p32.

Mapping of mouse agrin. Hybridization of the $2.5 \mathrm{~kb}$ mouse agrin probe to EcoRI-digested genomic DNA resulted in the detection of an $11 \mathrm{~kb}$ Chinese hamster (Fig. 6, right, lane 1) and a $4 \mathrm{~kb}$ mouse (Fig. 6, right, lane 2) fragment. The $4 \mathrm{~kb}$ mouse fragment was present in the hybrid cell lines that had retained

Figure 2. Intron-exon junctions in the mouse agrin gene. The nucleotide sequence through the RNA splicing junctions of the 36 exons is presented. The nucleotides in lowercase are intron sequence, while the nucleotides in uppercase are exon sequence. Each acceptor site conforms to the AG consensus, while each donor site conforms to the GT consensus. The amino acid sequence at each of the exon borders is written above the second nucleotide of the codon, and the amino acids are numbered according to the rat agrin sequence of Rupp et al. (1991). The length of the rat exons in nucleotides is written between the acceptor and donor borders. Two acceptor sites are utilized for exon 20 (denoted $20 \mathrm{a}$ and $20 \mathrm{~b}$ ), and exons 32 and 33 encode the alternatively spliced regions presented in Figure $1 B$. The last exon encodes the complete $3^{\prime}$ untranslated region up to the polyA site. The stop codon is indicated by an asterisk $\left(^{*}\right)$ and is located at amino acid position 1941 in Rupp et al. (1991). The GenBank accession numbers for the mouse genomic sequence are M92654-M92659. 


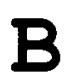

\section{R-AGRN1 (1287) \\ R-AGRN2 (1555) \\ R-AGRN3 (1788)}

\section{M-AIAMI}

M-AIAM2

H-MRSN1

H-MRSN2

H-MRSN3

\begin{abstract}
LAIEFRA LETE CWWL NNENAR-GR-DFWRLALLDERVQFRFDTGSCPAVUTSLVPVEPG

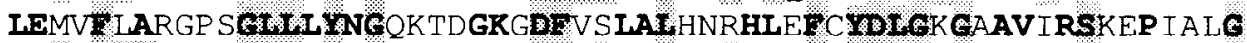
FEIS LRTEAT QEUVLW I GKAAERA-DYMATAA IVDEHLQLS YOLES QPVVLRSTVKVNTN
\end{abstract}

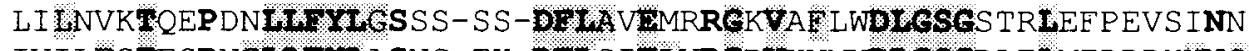

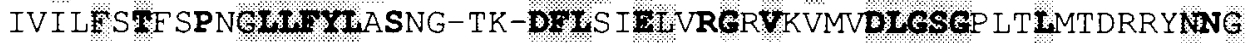

IVVNVKTAVADNLWFYUESAK-F I-DEI.A I EMRK EKVS F LWBVESGVGRVEYPDLT IDD

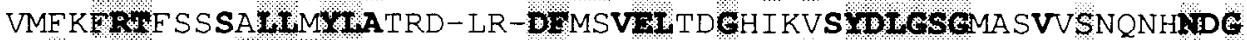

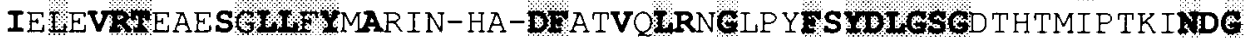

\section{R-AGRN1 \\ R-AGRN2 \\ R-AGRN3

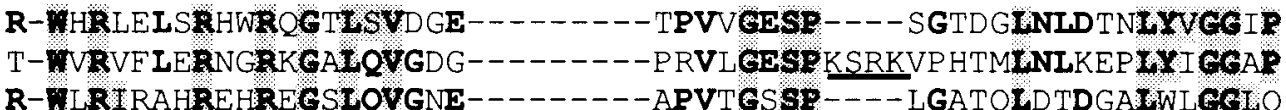

Figure 4. Two repeats in the agrin protein. $A$, Exons 10 and 16 contain a conserved motif of four cysteine and three proline residues. The numbering corresponds to the amino acids in Rupp et al. (1991). B, $R$-AGRN1 (amino acids 1287-1390; exons 21-22; Rupp et al., 1991), $R-A G R N 2$ (amino acids 1555-1664; exons 26-29), and $R-A G R N 3$ (amino acids 1788-1892; exons 34-35) are repeated motifs. In this region, 43\% of the amino acids are identical, as indicated by bold type. The underlined sequence $(K S R K)$ in $R-A G R N 2$ is encoded by exon 28 . In the mouse laminin A chain (M-ALAMI and $M$-ALAM2), amino acids 2086-2198 and 2273-2384 (Sasaki et al., 1988) are 32\% identical, as indicated by the bold type. In human merosin (H-MRSN1. H-MRSN2, H-MRSN3), amino acids 190-305, 384-494, and 809-911 (Ehrig et al., 1990) share identical amino acids in two of every three positions at $50 \%$ of the residues, as indicated by the bold type, and identical amino acids in all positions at $16 \%$ of the residues. The shading indicates a common core sequence shared by all of the domains in the three proteins. One-third of the residues are identical in at least four of eight positions.

mouse chromosome 4 . All other mouse chromosomes were excluded by at least two discordant hybrids (Table 2). Thus, the mouse agrin gene (gene symbol $\mathrm{Agrn}$ ) can be assigned to chromosome 4.

We have searched for polymorphisms using two mouse genomic agrin DNA probes. A BamHI-BamHI fragment including exons 1-6, and a HindIII-NotI fragment including exon 36 and a region 3 ' to the gene (Fig. 3). No strain differences were detected with BamHI, PstI, EcoRI, BglII, and HindIII in five inbred mouse strains, AKR/J, C3H/HeJ, C57BL/6J, C57L/J, and DBA/2J.

\section{Discussion}

The domain structure of agrin. This report characterizes the DNA and RNA that code for mammalian agrin. The clear domain structure revealed by analysis of the predicted amino acid sequence is further revealed by the agrin genomic organization presented here. The amino terminus regions homologous to protease inhibitors are each encoded by a separate exon, suggesting that this portion of agrin evolved through a series of unequal crossover events that produced a tandem array of these units. The fact that protease inhibitor repeats 8 and 9 have an internal intron suggests one of two scenarios. First, it is possible that the original protease inhibitor domain contained this intron and that a unit that had deleted the intron was amplified, resulting in the seven amino terminal protease inhibitor domains. Alternatively, it is possible that the insertion of sequences produced an intron and that a single duplication then resulted in units 8 and 9 . The first hypothesis is supported by the following observation: the exons that encode the first half of the protease inhibitor domains 8 and 9 (exons 8 and 13, respectively) contain a sequence that resembles an EGF repeat more than a protease inhibitor domain. In many EGF repeat containing proteins, such as the EGF precursor, the LDL receptor (Südhof et al., 1985), protein S (Schmidel et al., 1990), and cartilage matrix protein 
1

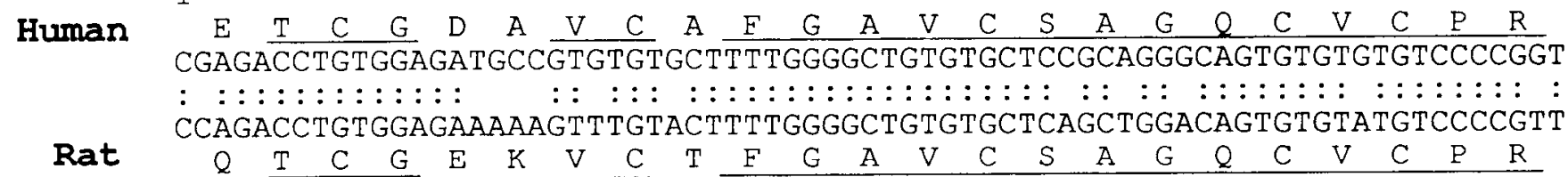
1683

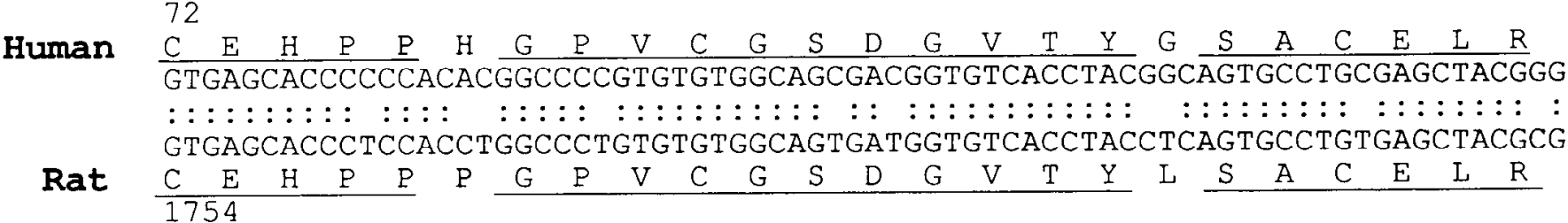

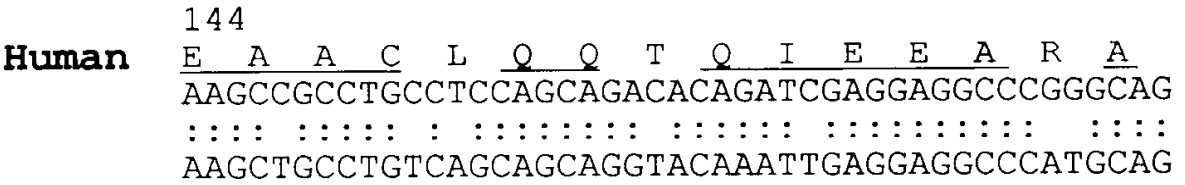

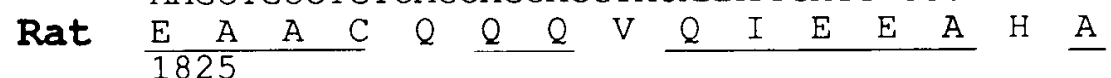

Figure 5. DNA and protein alignment of a portion of human and rat agrin cDNAs. The nucleotide sequence is numbered above for the human cDNA and below for the rat cDNA, according to Rupp et al. (1991). The identical nucleotides are indicated by (:), and the identical amino acids are underlined. Twenty-nine nucleotide differences between human and rat result in nine amino acid substitutions in this region of the agrin protein.

(Kiss et al., 1989), the EGF repeat domains are individually encoded on separate exons. This suggests that agrin protease inhibitor domains 8 and 9 were formed by rearrangement of an EGF repeat exon and a protease inhibitor exon sequence. The model is supported by the observation that strong homology to pancreatic secretory trypsin inhibitors is on the carboxy terminal side of the intron.

The analysis of ovoinhibitor, a Kazal-type serine protease inhibitor with seven tandem inhibitor units, has revealed introns flanking the individual domains (Stein et al., 1980; Scott et al., 1987). Thus, a common theme of internal duplication to generate tandem protease inhibitor-like units appears to have played a significant role in the evolution of both agrin and the Kazal family of proteins. Ovoinhibitor and ovomucoid also contain introns within the Kazal protease inhibitor domains. One of these introns is located four amino acids carboxy-terminal to the fifth cysteine residue of the inhibitor domain. Interestingly, while all of the agrin cysteine residues align with the Kazal inhibitor motif rather precisely, the fifth cysteine is displaced to precisely the position of this intron. Thus, rearrangement near this intron site may be responsible for the cysteine pattern present in agrin.

The intervening sequences in the agrin laminin domain III homologous regions (exons 11 and 12) are found in positions similar to those of introns in domain III of the laminin A chain (Vuolteenaho et al., 1990). This organization strongly favors the hypothesis that exon shuffling from a common progenitor has generated these domains. Agrin also contains regions that are homologous to the $\mathrm{G}$ domain of laminin $\mathrm{A}$ and merosin. The $\mathrm{G}$ region is a large globular domain that is proposed to bind heparin (Sakashita et al., 1980; Ott et al., 1982). Perhaps this region of agrin is involved in the binding of heparan sulfate proteoglycans. This hypothesis is supported by the finding that an addition of heparin to the culture medium inhibits the formation of agrin-induced clusters of AChR. One of the agrin regions homologous to the laminin $\mathrm{G}$ domain has a basic, 4 amino acid insert that is encoded on a distinct exon. These basic amino acids may modulate the interactions with proteoglycans.

Table 1. AGRN sequences and human chromosomes in rodent $\times$ human somatic cell hybrids

\begin{tabular}{|c|c|c|c|c|c|c|c|c|c|c|c|c|c|c|c|c|c|c|c|c|c|c|c|}
\hline \multirow{2}{*}{$\begin{array}{l}\text { Human } A G R N \\
\text { sequences/chromosome }\end{array}$} & \multicolumn{23}{|c|}{ Human chromosome } \\
\hline & $\overline{1}$ & 2 & 3 & 4 & 5 & 6 & 7 & 8 & 9 & 10 & 11 & 12 & 13 & 14 & 15 & 16 & 17 & 18 & 19 & 20 & 21 & 22 & $x$ \\
\hline \multicolumn{24}{|l|}{ Concordant hybrids } \\
\hline$+1+$ & 5 & 2 & 3 & 2 & 0 & 4 & 0 & 4 & 1 & 1 & 1 & 3 & 1 & 4 & 3 & 4 & 1 & 4 & 4 & 1 & 4 & 5 & 1 \\
\hline$-1-$ & 8 & 7 & 3 & 5 & 6 & 5 & 6 & 6 & 6 & 7 & 2 & 6 & 4 & 2 & 4 & 5 & 7 & 4 & 4 & 4 & 5 & 5 & 1 \\
\hline \multicolumn{24}{|l|}{ Discordant hybrids } \\
\hline$+1-$ & 0 & 3 & 2 & 2 & 5 & 1 & 3 & 1 & 4 & 4 & 2 & 2 & 4 & 1 & 2 & 1 & 4 & 1 & 0 & 4 & 0 & 0 & 0 \\
\hline$-1+$ & 0 & 2 & 6 & 3 & 3 & 3 & 2 & 3 & 2 & 1 & 7 & 3 & 5 & 5 & 5 & 3 & 1 & 4 & 5 & 5 & 4 & 3 & 2 \\
\hline Total discordant hybrids & 0 & 5 & 8 & 5 & 8 & 4 & 5 & 4 & 6 & 5 & 9 & 5 & 9 & 6 & 7 & 4 & 5 & 5 & 5 & 9 & 4 & 3 & 2 \\
\hline Total informative hybrids ${ }^{a}$ & 13 & 14 & 14 & 12 & 14 & 13 & 11 & 14 & 13 & 13 & 12 & 14 & 14 & 12 & 14 & 13 & 13 & 13 & 13 & 14 & 13 & 13 & 4 \\
\hline
\end{tabular}

${ }^{a}$ Chromosomes with rearrangements or present at a frequency of 0.1 or less were excluded. 


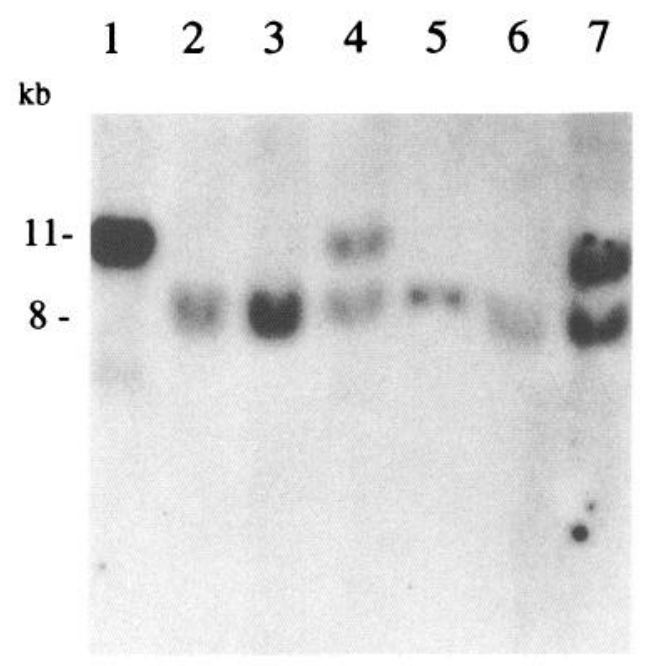

Human

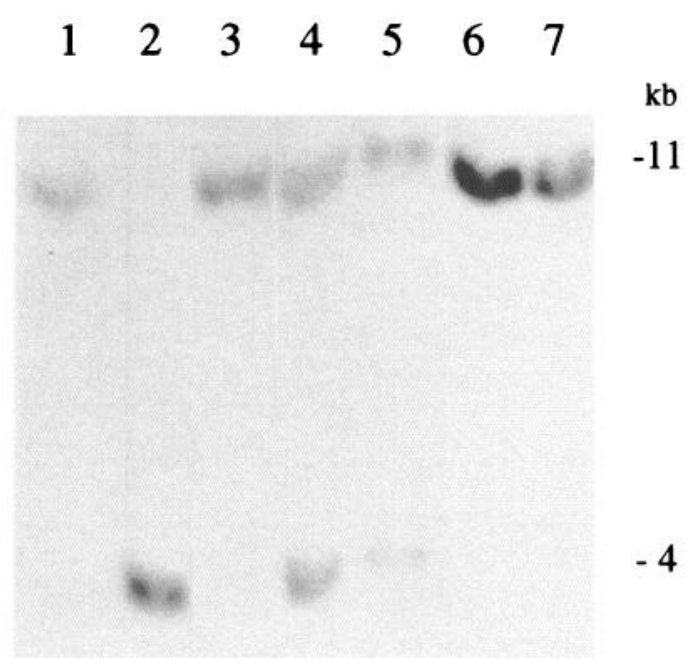

Mouse

\section{AGRN}

Figure 6. Mapping of agrin gene in human (left) and mouse (right). ${ }^{32} \mathrm{P}$-Labeled agrin probe was hybridized to a Southern blot of BamHI-digested human $\times$ Chinese hamster DNA samples $(l e f t)$ or EcoRI-digested Chinese hamster $\times$ mouse DNA samples $($ right $)$ and controls. Fragment sizes (in kb) are indicated. Left: Lane 1, human lymphoblastoid cell line; lane 2, Chinese hamster cell line V79/380-6; lanes 3-7, hybrid cell lines of which lanes 4 and 7 are positive, and lanes 3, 5, and 6 are negative for the human-specific signal. Right: Lane 1, Chinese hamster cell line V79/ 380-6; lane 2, mouse cell line 3T3; lanes 3-7, hybrid cell lines of which lanes 4 and 5 are positive and lanes 3, 5, and 7 are negative for the mousespecific signal.

It is noteworthy that the genomic organization of agrin and many other proteins containing repeated domains appears to be very similar, in that the individual repeats are encoded by independent exons. This observation supports the original proposal by Gilbert $(1985,1987)$, suggesting that a pool of exons encoding distinct functional and structural domains may have been shuffled during evolution to generate new proteins. In this case, it appears that shuffling of exons between extracellular matrix proteins has played a role in the evolution of these molecules. These shuffling mechanisms are likely to have been important in the evolution of the protein-protein interactions that generate the scaffold structure of the extracellular matrix.

Alternative RNA splicing. The alternative RNA splicing of the mammalian agrin gene is interesting in a variety of contexts. First, two different organizations of acceptor and donor sequences are used. While exon 20 presents two acceptor sites to the donor site of exon 19, the organization of splicing in the carboxy terminal region of the protein is quite different. Here, two independent exons are spliced in the four possible config- urations. If exon 31 is spliced to exon 34 , as most often appears to happen based on the relative abundance of cDNAs, the effective intron is about 1058 nucleotides, the largest in the gene. The two alternatively spliced regions are among the smallest exons in the gene, 24 and 33 nucleotides, respectively.

The AChR clustering activity of the four differentially spliced products at position 1779 has recently been investigated (Ferns et al., in press). The four forms of the protein, either containing no exon sequences at position $1779\left(\mathrm{agrin}_{0}\right)$, the 8 amino acid exon $\left(\operatorname{agrin}_{8}\right)$, the 11 amino acid exon $\left(\operatorname{agrin}_{11}\right)$, or the 8 and the 11 amino acid exons (agrin ${ }_{19}$ ), were expressed in $\mathrm{CHO}$ and $\mathrm{COS}$ cells. Coculture of the transfected cells with primary muscle cells or myotubes derived from the $\mathrm{C} 2$ muscle cell line results in AChR clusters at all cell-cell contact sites. Coculture experiments were also conducted with $\mathbf{S} 27$ cells, myoblasts that synthesize altered proteoglycans. Only agrin ${ }_{8}$ and agrin ${ }_{19}$ are able to induce AChR clusters at contact sites on S27 derived myotubes. In addition, only agrin ${ }_{8}$ and agrin ${ }_{19}$ are effective in inducing AChR clusters on chick myotubes. These studies suggest

Table 2. Presence of mouse Agrn sequences and mouse chromosomes in mouse $\times$ Chinese hamster somatic cell hybrids

\begin{tabular}{|c|c|c|c|c|c|c|c|c|c|c|c|c|c|c|c|c|c|c|c|c|}
\hline \multirow{2}{*}{$\begin{array}{l}\text { Mouse Agrn/ } \\
\text { chromosome }\end{array}$} & \multicolumn{20}{|c|}{ Mouse chromosome } \\
\hline & 1 & 2 & 3 & 4 & 5 & 6 & 7 & 8 & 9 & 10 & 11 & 12 & 13 & 14 & 15 & 16 & 17 & 18 & 19 & $x$ \\
\hline \multicolumn{21}{|l|}{ Concordant hybrids } \\
\hline$+1+$ & 3 & 7 & 5 & 6 & 3 & 4 & 6 & 5 & 1 & 2 & 0 & 4 & 2 & 3 & 6 & 3 & 6 & 4 & 7 & 4 \\
\hline$-1-$ & 1 & 2 & 3 & 5 & 3 & 2 & 2 & 3 & 3 & 3 & 5 & 2 & 4 & 4 & 1 & 1 & 2 & 4 & 2 & 1 \\
\hline \multicolumn{21}{|l|}{ Discordant hybrids } \\
\hline$+1-$ & 3 & 0 & 2 & 0 & 3 & 2 & 1 & 2 & 6 & 4 & 7 & 3 & 4 & 3 & 1 & 2 & 1 & 3 & 0 & 2 \\
\hline$-1+$ & 3 & 3 & 2 & 0 & 1 & 3 & 2 & 2 & 2 & 2 & 0 & 3 & 1 & 1 & 4 & 4 & 3 & 0 & 2 & 4 \\
\hline Total discordant hybrids & 6 & 3 & 4 & 0 & 4 & 5 & 3 & 4 & 8 & 6 & 7 & 6 & 5 & 4 & 5 & 6 & 4 & 3 & 2 & 6 \\
\hline Total informative hybrids ${ }^{a}$ & 10 & 12 & 12 & 11 & 10 & 11 & 11 & 12 & 12 & 11 & 12 & 12 & 11 & 11 & 12 & 10 & 12 & 11 & 11 & 11 \\
\hline
\end{tabular}

${ }^{a}$ Chromosomes with rearrangements or present at a frequency of 0.1 or less were excluded. 
the following AChR clustering activity profile for the different forms of rat agrin: $0 \leq 11<19 \leq 8$. Thus, the alternative RNA splicing we have described here regulates the AChR clustering activity of the agrin proteins on a variety of cultured myotubes and may also do so in vivo.

We do not yet know the tissue specificity of the alternatively spliced agrin forms. For instance, agrin is expressed in brain, muscle, and areas of the spinal cord, including motor neurons. It is possible that the forms of agrin most active in AChR clustering are preferentially expressed in motor neurons. Differential splicing of agrin transcripts could also be regulated by developmental and physiological conditions. Perhaps various agrin isoforms are expressed at different stages of development, or in response to physiological changes, such as during reinnervation following nerve damage.

The agrin gene locus. Mapping of the agrin gene locus in the human and mouse genomes was undertaken to determine whether the gene is colocalized with a neuromuscular disease gene in humans or a neurological mutation in mouse. The human agrin gene (AGRN) has been mapped to the distal short arm of chromosome 1 (HSA 1), bands pter-p32, by Southern blot analysis of DNA from Chinese hamster $x$ human hybrid cell lines. So far, the only neuromuscular disorder that has been assigned to this region of chromosome 1 is the Finnish type of infantile neuronal ceroid-lipofuscinosis (Jarvela et al., 1991). This disorder is due to a disturbance of linoleic acid metabolism and, therefore, not a likely candidate for an agrin mutation.

The murine Agrn locus has been mapped to mouse chromosome 4 (MMU 4) with a panel of Chinese hamster $\times$ mouse hybrid lines. The human chromosome region Ipter-p32 is homologous to the distal half of MMU 4. There are 14 other homologous genes in these regions (see Davisson et al., 1990, for review). There are three neurological mutations on MMU 4 in the conserved region that could involve Agrn. In cribriform degeneration (cri), homozygotes have abnormal behavior, anemia, and electrolyte imbalance. Severe vacuolar degeneration is present in white and gray matter of brainstem, spinal cord, and retina (Green et al., 1972). The recessive mutation je (jerker) is associated with hyperactivity, circling, head tossing, deafness, and postnatal degeneration of the sensory cells of the cochlea, sacculus, and utriculus (Grüneberg et al., 1941; Deol, 1954; Steel and Bock, 1983). Another recessive mutation, cla (clasper), is characterized by small size, fine body tremor, and clasping of forefeet and hindfeet (Sweet, 1985). Before embarking on any direct mutational analysis, it will be necessary to map the mouse Agrn locus more precisely by using interspecies crosses, since no polymorphism was detected in progenitor strains of common RI strains.

Characterization of the mammalian agrin gene presented here is the beginning of a new era in understanding the function of this protein. We are now in a position to use mouse genetics and transgenic techniques to evaluate further the function of agrin in synapse development and disease states.

\section{References}

Anderson MJ, Cohen MW, Zorychta E (1977) Effects of innervation on the distribution of acetylcholine receptors on cultured muscle cells. J Physiol (Lond) 268:731-756.

Andreadis A, Gallego M, Nadal-Ginard B (1987) Generation of protein isoform diversity by alternative splicing: mechanical and biological implications. Annu Rev Cell Biol 3:207-242.

Barton DE, Yang-Feng TL, Francke U (1986) The human tyrosine aminotransferase gene mapped to the long arm of chromosome 16 (region 16q22-q24) by somatic cell hybrid analysis and in situ hybridization. Hum Genet 72:221-224.

Bayne EK, Anderson MJ, Fambrough DM (1984) Extracellular matrix organization in the developing muscle: correlation with acetylcholine receptor aggregates. J Cell Biol 99:1486-1501.

Bevan S, Steinbach JH (1977) The distribution of $\alpha$-bungarotoxin binding sites on mammalian skeletal muscle developing in-vivo. J Physiol (Lond) 267:195-213.

Campanelli JT, Hoch W, Rupp F, Kreiner T, Scheller RH (1991) Agrin mediates cell contact induced acetylcholine receptor clustering. Cell 67:909-916.

Davisson MT, Lalley PA, Peters J, Doolittle DP, Hillyard AL, Searle AG (1990) Report of the comparative subcommittee for human and mouse homologies. Cytogenet Cell Genet 55:434-456.

Deol MS (1954) The anomalies of the labyrinth of the mutants varitintwaddler, shaker-2, and jerker in the mouse. J Genet 52:562-588.

Ehrig K, Leivo I, Argraves WS, Ruoslahti E, Engvall E (1990) Merosin, a tissue-specific basement membrane protein, is a laminin-like protein. Proc Natl Acad Sci USA 87:3264-3268.

Fallon JR, Nitkin NE, Reist NE, Wallace BG, McMahan UJ (1985) Acetylcholine receptor-aggregating factor is similar to molecules concentrated at neuromuscular junctions. Nature 315:571-574.

Ferns M, Hoch W, Campanelli JT, Rupp F, Hall ZW, Scheller RH (1992) RNA splicing regulates agrin-mediated acetylcholine receptor clustering activity on cultured myotubes. Neuron, in press.

Fertuck HC, Salpeter MM (1974) Localization of acetylcholine receptor by ${ }^{125}$ I-labeled alpha bungarotoxin binding at mouse motor endplates. Proc. Natl Acad Sci USA 71:1376-1378.

Fertuck HC, Salpeter MM (1976) Quantitation of junctional and extrajunctional acetylcholine receptors by electron microscope autoradiographs after ${ }^{125} \boldsymbol{\alpha} \alpha$-bungarotoxin binding at mouse neuromuscular junctions. J Cell Biol 221:675-696.

Francke U, Yang-Feng TL, Brissenden JE, Ullrich A (1986) Chromosomal mapping of genes involved in growth control. Cold Spring Harbor Symp Quant Biol 51:855-866.

Froehner SC (1991) The submembrane machinery for nicotinic acetylcholine receptor clustering. J Cell Biol 1 14:1-7.

Froehner SC, Luetje CW, Scotland PB, Patrick J (1990) The postsynaptic $43 \mathrm{~K}$ protein clusters muscle nicotinic acetylcholine receptors in Xenopus oocytes. Neuron 5:403-410.

Gilbert W (1985) Genes-in-pieces revisited. Science 228:823-824.

Gilbert W (1987) The exon theory of genes. Cold Spring Harbor Symp Quant Biol 52:901-905.

Godfrey EW, Nitkin RM, Wallace BG, Rubin LL, McMahan UJ (1984) Components of Torpedo electric organ and muscle that cause aggregation of acetylcholine receptors on cultured muscle cells. J Cell Biol 99:615-627.

Green MC, Sidman RL, Pivetta DH (1972) Cribriform degeneration (cri): a new recessive neurological mutation in the mouse. Science 176:800-803.

Grüneberg H, Burnett JB, Snell GD (1941) The origin of jerker, a new gene mutation of the mouse, and linkage studies made with it. Proc Natl Acad Sci USA 27:562-565.

Hall ZW (1973) Multiple forms of acetylcholinesterase and their distribution in endplate and non-endplate regions of rat diaphragm muscle. J Neurobiol 4:343-361.

Hunter DD, Shah V, Merlie JP, Sanes JR (1989) A laminin-like adhesive protein concentrated in the synaptic cleft of the neuromuscular junction. Nature 338:229-234.

Indik Z, Yeh H, Ornstein-Goldstein N, Sheppard P, Anderson N, Rosenbloom JC, Peltonen L, Rosenbloom J (1987) Alternative splicing of human elastin mRNA indicated by sequence analysis of cloned genomic and complementary DNA. Proc Natl Acad Sci USA 84: 5680-5684.

Jarvela I, Schleutker J, Haataja L, Santavuori P, Puhakka L, Manninen T, Palotie A, Sandkuijl LA, Renlund M, White R, Aula P, Peltonen L (1991) Infantile form of ncuronal ccroid lipofuscinosis (CLN1) maps to the short arm of chromosome 1. Genomics 9:170-173.

Kiss I, Deak F, Holloway RG, Delius H, Mebust KA, Frimberger E, Argraves WS, Tsonis PA, Winterbottom N, Goetinick PF (1989) Structure of the gene for cartilage matrix protein, a modular protein of the extracellular matrix. J Biol Chem 264:8126-8134.

Kornblihtt AR, Umezawa K, Vibe-Pedersen K, Baralle F (1985) Primary structure of human fibronectin: differential splicing may gen- 
erate at least 10 polypeptides from a single gene. EMBO J 4:17551759.

Magill-Solc C, McMahan UJ (1988) Motor neurons contain agrin-like molecules. J Cell Biol 107:1825-1833.

Magill-Solc C, McMahan UJ (1990) Synthesis and transport of agrinlike molecules in motor neurons. J Exp Biol 153:1-10.

McMahan UJ (1990) The agrin hypothesis. Cold Spring Harbor Symp Quant Biol 55:407-418.

McMahan UJ, Wallace BG (1989) Molecules in basal lamina that dircct the formation of synaptic specializations at neuromuscular junctions. Dev Neurosci 11:227-247.

Nitkin RM, Rothschild TC (1990) Agrin-induced reorganization of extracellular matrix components on cultured myotubes: relationships to AChR aggregation. J Cell Biol 111:1161-1170.

Nitkin RM, Smith MA, Magill C, Fallon JR, Yao YM, Wallace BG, McMahan UJ (1987) Identification of agrin, a synaptic organizing protein from Torpedo electric organ. J Cell Biol 105:2471-2478.

Ott U, Odermatt E, Furthmayr H, Timpl R (1982) Protease resistance and conformation of laminin. Eur J Biochem 123:63-72.

Peng HB, Baker LP, Chen Q (1991) Induction of synaptic development in cultured muscle cells by basic fibroblast growth factor. Neuron 6 : 237-246.

Phillips WD, Kopta C, Blount P, Gardner PD, Steinbach JH, Merlie JP (1991) ACh receptor-rich membrane domains organized in fibroblasts by recombinant 43-kilodalton protein. Science 251:568570.

Pihlajaniemi T, Myllyla R, Seyer J, Kurkinen M, Prockop DJ (1987) Partial characterization of a low molecular weight human collagen that undergoes alternative splicing. Proc Natl Acad Sci USA 84:940944.

Qu Z, Moritz E, Huganir RL (1991) Regulation of tyrosine phosphorylation of the nicotinic acetylcholine receptor at the rat neuromuscular junction. Neuron 4:367-378.

Reist NE, Magill C, McMahan UJ (1987) Agrin-like molecules at synaptic sites in normal, denervated, and damaged skeletal muscles. J Cell Biol 105:2457-2469.

Rupp F, Payan DG, Magill-Solc C, Cowan DM, Scheller RH (1991) Structure and expression of rat agrin. Neuron 6:811-823.

Ryan MC, Sandell LJ (1990) Differential expression of a cysteine-rich domain in the amino-terminal propeptide of type II (cartilage) procollagen by alternative splicing of mRNA. J Biol Chem 265:1033410339.

Sakashita S, Engvall E, Ruoslahti E (1980) Basement membrane glycoprotein laminin binds to heparin. FEBS Lett 116:243-246.

Sasaki M, Kleinman HK, Huber H, Deutzmann R, Yamada Y (1988) I aminin A multidomain protein. J Biol Chem 263:16536-16544.
Schmidel DK, Tatro AV, Phelps LG, Tomczak JA, Long GL (1990) Organization of the human protein $S$ genes. Biochemistry 29:78457852.

Schuetze SM, Role LW (1987) Developmental regulation of nicotinic acetylcholine receptors. Annu Rev Neurosci 10:403-457.

Schwarzbauer JE, Patel RS, Fonda D, Hynes RO (1987) Multiple sites of alternative splicing of the rat fibronectin gene transcript. EMBO J 6:2573-2580.

Scott MJ, Huckaby CS, Katos I, Kohr W, Laskowski M, Tsai M-J, O'Malley BW (1987) Ovoinhibitor introns specify functional domains as in the related and linked ovomucoid gene. J Biol Chem 262: 5899-5907.

Steel KP, Bock GR (1983) Cochlear dysfunction in the jerker mouse. Behav Neurosci 97:381-391.

Stein JP, Catterall JF, Kristo P, Means AR, O'Malley BW (1980) Ovomucoid intervening sequences specify functional domains and generate protein polymorphism. Cell 21:681-687.

Südhof TC, Russell DW, Goldstein IL, Brown MS, Sanchez-Pescador R, Bell GI (1985) Cassette of eight exons shared by genes for LDL receptor and EGF precursor. Science 228:893-895.

Svoboda KK, Nishimura I, Sugrue SP, Nimomiya Y, Olsen BR (1988) Embryonic chicken cornea and cartilage synthesize type IX collagen molecules with different amino-terminal domains. Proc Natl Acad Sci USA 85:7496-7500.

Sweet HO (1985) Mouse News Lett 73:18.

Tikka L, Roiko K, Soininen R, Prockop DJ, Tryggvason K (1987) A Hind III polymorphism in the $3^{\prime}$ end of the human alpha 1 (IV) collagen gene. Nucleic Acids Res 15:5497.

Vuolteenaho R, Kallunki T, Chow L, Ikonen I, Pikkarainen T, Tryggvason K (1990) Genes for the human laminin B1 and B2 chains. In: Extracellular matrix genes, pp 175-193. San Diego: Academic.

Wallace BG (1986) Aggregating factor from Torpedo electric organ induces patches containing acetylcholine receptors, acetylcholinesterase, and butyrylcholinesterase on cultured myotubes. J Cell Biol 102:783-794.

Wallace BG (1989) Agrin-induced specializations contain cytoplasmic, membrane, and extracellular matrix-associated components of the postsynaptic apparatus. J Neurosci 9:1294-1302.

Wallace BG, Qu Z, Huganir RL (1991) Agrin induces phosphorylation of the nicotinic acetylcholine receptor. Neuron 6:869-878.

Weinberg CB, Sanes JR, Hall ZW (1981) Formation of neuromuscular junctions in adult rats: accumulation of acetylcholine receptors, acetylcholinesterase and components of synaptic basal lamina. Dev Biol 84:255-266. 